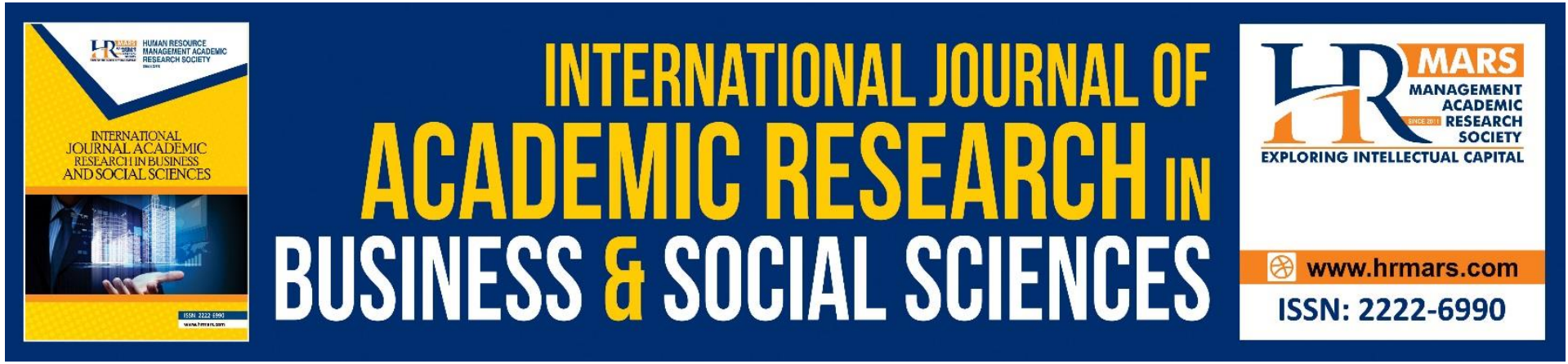

\title{
Factors Influencing The Fans Decision Between Genders to Attend Football Matches at Larkin Stadium
}

\section{Azman Ahmad Tajri, Ahmad Nurhakim Iskandar}

To Link this Article: http://dx.doi.org/10.6007/IJARBSS/v11-i9/10854

DOI:10.6007/IJARBSS/v11-i9/10854

Received: 20 July 2021, Revised: 25 August 2021, Accepted: 01 September 2021

Published Online: 19 September 2021

In-Text Citation: (Tajri \& Iskandar, 2021)

To Cite this Article: Tajri, A. A., \& Iskandar, A. N. (2021). Factors Influencing The Fans Decision Between Genders to Attend Football Matches at Larkin Stadium. International Journal of Academic Research in Business and Social Sciences, 11(9), 1227-1237.

\section{Copyright: @ 2021 The Author(s)}

Published by Human Resource Management Academic Research Society (www.hrmars.com)

This article is published under the Creative Commons Attribution (CC BY 4.0) license. Anyone may reproduce, distribute, translate and create derivative works of this article (for both commercial and non-commercial purposes), subject to full attribution to the original publication and authors. The full terms of this license may be seen at: http://creativecommons.org/licences/by/4.0/legalcode

Vol. 11, No. 9, 2021, Pg. 1227 - 1237

Full Terms \& Conditions of access and use can be found at http://hrmars.com/index.php/pages/detail/publication-ethics 


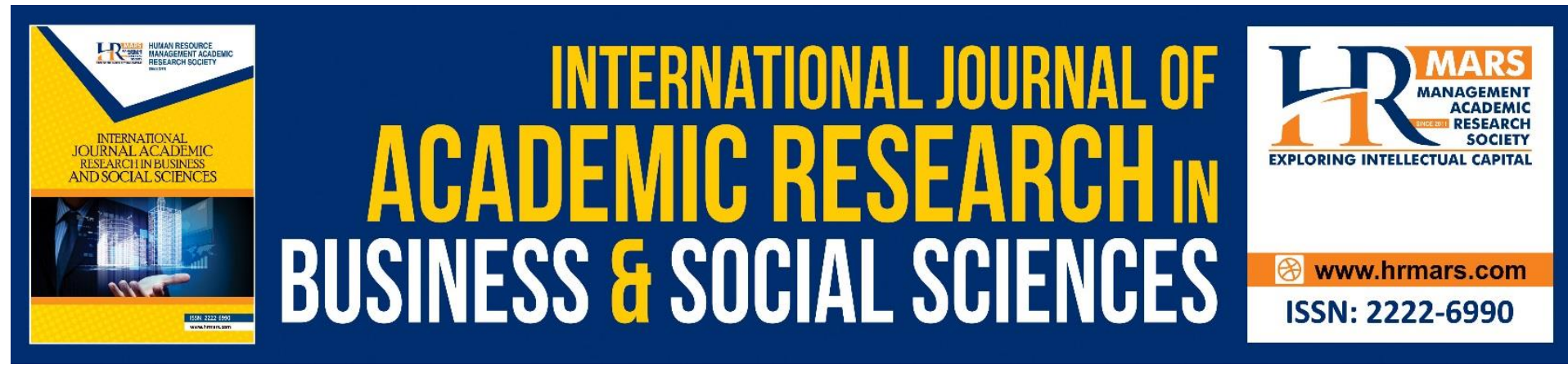

\title{
Factors Influencing The Fans Decision Between Genders to Attend Football Matches at Larkin Stadium
}

\author{
Azman Ahmad Tajri, Ahmad Nurhakim Iskandar \\ Faculty of Sport Science and Recreation, Universiti Teknologi MARA, Negeri Sembilan \\ Branch, Seremban Campus
}

\begin{abstract}
This study was aimed to investigate the factors influencing the fans decision between genders to attend football matches at Larkin Stadium. This study was designed to identify the factor that most influences fan attendance during football matches at Larkin Stadium. A total of 409 Boys of Straits Johor football fans, which consists of 223 men and 186 women were involved as the main respondents in this research. For the purposed of this study, the questionnaires were adapted and adopted from Shobian (2016) to find out which factors that motivates individuals to attend football matches at Larkin Stadium. The result showed that the social aspects with mean 4.06 and standard deviation 0.64 turned out to be the one factor that most influences fan's attendance during football matches at Larkin Stadium. The result showed that there was significant difference in residual preferences factor between genders $(t)(407.0)=$ 3.179; $p<0.05)$, economics factor between genders ( $t(407.0)=3.507 ; p<0.05)$, team identification factor between genders $(\mathrm{t}(407.0)=4.003 ; \mathrm{p}<0.05)$ and team affiliation factor between genders $(\mathrm{t}(407.0)=3.192 ; \mathrm{p}<0.05)$. The result also showed that there was no significant difference in social aspects factor between genders $(t(407.0)=1.501 ; p>0.05)$ and economics factor between genders $(t(407.0)=4.003 ; p<0.05)$. This finding will help the organization to recognize the factors that influence the fans attendance during football matches at Larkin Stadium and make improvements in attracting fans to the stadium.
\end{abstract}

Keywords: Factors Influencing Fans Decision, Attend Football Matches, Football Fans.

\section{Introduction}

According to Brandon, Wen-Hao and James (2018) described sports fans are individuals who are interested in and follow a sport, team and athlete. These fans reinforce their identity as a fan by engaging in supportive and repetitive consumption behaviours that relate to the sport or team they are so passionate about. In Malaysia, football is the number one sport. Approximately 10 million people show an active interest in it, in a total population of 32 milion(Phillips, 2018). Football is more than just a sport in the country. It brings people together and no matter their background or social class. According to Bianca-Rose (2018), the population of Malaysia is composed of men than women, $56 \%$ compared to $44 \%$. The first discovery was that $60 \%$ of football fans in the country are males and $40 \%$ females. The study also examined that the majority of football fans in Malaysia are millennial, with $67.5 \%$ of the 
target audience between 18 and 34 years old. The oldest age group shows very little interest in the sport just $1.4 \%$ of 65 years old and above(Phillips, 2018).

According to statistics released by the Malaysian Football League (MFL), My Metro (2019), Johor Southern Tiger (JST) recorded the highest number of fans in Malaysia for five consecutive years from 2015 to 2019. Based on the article, record has shown that Johor Darul Ta'zim FC (JDT FC) has succeeded in attracting fans to the stadium to watch their game consistently. At the end of the 2019 season, the Johor Darul Takzim FC (JDT FC) accumulated 196, 858 fans to attend all the games at Larkin Stadium (Msar, 2019).

Previous researchers have found that certain sociodemographic variables are highly related to the level of game consumption, such as gender, age, ethnicity, occupation, education and household income. In the 2008 Survey of Public Participation in the Arts done by the National Endowment for the Arts, it was found that $30.6 \%$ of American adult population attended at least one sport event in the past 12 months. Among these sport attendees, $54.9 \%$ were male while $45.1 \%$ were female. Younger adults from age 18 to 24 were most likely to attend a sporting event. Furthermore, these sporting event attendees were more likely to be higher educated and of higher income than the non-attendees and were more likely to be white than Hispanic or African-American.

Similarly, another survey done by the Pew Research Center in 2006 indicated that about one half of all Americans claimed to follow sports and more than twice as many males as females followed sports very closely. Data from previous studies revealed that more spectators come from households of two to four people with higher than average incomes(Beth A. Cianfrone, 2015). In some specific sports, previous research findings also revealed that the sociodemographic backgrounds of fans and spectators might vary. For example, young to middle-aged Caucasian males are most likely to attend professional basketball games and they also represent close to $50 \%$ of the audience at major league professional sporting events(Beth A. Cianfrone, 2015). As for the professional and amateur female sporting events, the fan base is young to meddle-aged Caucasian females(Havitz, 2010). As previous research findings have shown, sport fandom can come from a diverse background of sociodemographic categories.

Every football club wants its own new stadium nowadays. But how to get maximized attendance rates? Professional football clubs cannot survive without fans so research about their possible constraints is necessary. Football clubs need to know how to organize their venue in order to connect fans or supporters. Society today considers football to be a source of entertainment that can be done. Other entertainment sectors are focusing heavily on visitor comfort(Thielen, 2018).

\section{Literature Review}

There are six influencing factors among fan's that were selected which are residual preferences, economics, social aspects, enjoyment, team identification and team affiliation. Motivations for various sporting activities are believed to be related and identical. There are several studies that have been completed in the classroom environment. The study has been done about the presence of supporters who attend sports events that have been obtained from books or articles(Havitz, 2010)

Residual preference factor is based on variables through the environment at all sporting events such as how the training is conducted, how a coach shows his abilities, how the cheerleading team shows their enthusiasm during the match and the fans who watch the match in groups. At college, the aspect was widely studied by Hill \& Green (2000), these 
factors can also be attributed to when the sports day will be organized, the weather conditions such as rain and the attraction of the fans through the cleanliness of the venue and the behavior of the fans during the previous sports day. The researchers also found that the maintenance of the venue during the sporting event was in good condition.

Economic factors play an important role in the participation of the football team such as how inspired the fans, various price dispersions and the consequence. Price dispersal is a phenomenon where different prices for the same commodity are sold by the same or different sellers. This represents the market's misunderstanding of the inclination for consumer purchases and activities(Jr., 2016). The main cause of this price spread is due to the company being completely unsure about the type of goods and they are also not sure to provide services to the goods they sell (Soebbing, 2014).

In order to socialize, be entertained and relax from their everyday working life, there are fans that frequent sporting activities. The desire to socialize with friends and family members is mainly used and correlated with all the big sporting activities (Hall, A model of predictors of attendance at major sporting events, 2009). To feel relax and escape from their daily activities, individuals attend sports. The bonding of the group is established, and social contact is formed. According to Hudson (2010), the factors affecting the decisions of students from California Polytechnic University to attend sporting events and theatrical performances are decided by social interactions. As opposed to watching events at the Performing Arts Center, the purpose of the research was to investigate the impact of attending athletic activities on students' decisions at Cal Poly. About two hundred students in nine classes are the test materials at Cal Poly's Spring Quarter. Studies show that social networking is the main reason they are present to watch sports events. This study also found that the percentages of those who attend sports events are high compared to those attending theater and other activities. Social networking was the top incentive for students to attend games. Among the reasons for such students not attending sports events and theater activities is the lack of time(Hudson, 2010).

Enjoyment or entertainment is one of the factors that can increase the number of fans to attend sporting events. Their attendance at sporting events is to reduce work stress, spend time with family and friends, calm the mind and so on(Jr., 2016). According to Hall (2009), it is said that the entertainment factor generates an atmosphere of enjoyment and ignites levels of excitement within an event. This factor can also create a comfortable atmosphere with the availability of well-equipped facilities such as adequate seating facilities, adequate parking facilities, clean toilet facilities and the provision of food and beverages that have been provided. Many past studies have shown that the provision of well-equipped facilities and venues is able to meet the needs of fans to regularly attend sporting events. Different surveys have shown that as part of their entertainment bundles, consumers include stadiums and include all the visual features as an important aspect impacting their decision-making on sports.

According to Hill \& Green (2000), a fan is affiliated with and maintains a loyalty with the team. If a fan associates with the franchise and appears to partake in several of the team's athletic activities, it is faithful. When the team loses or wins, both pleasure and sorrow are correlated with this relationship. Fans will always be with their team in any difficult or easy situation. The supporters will also always talk about the status of their team whenever there are friends or relatives as well as their acquaintances that represent the team. This can indirectly strengthen the relationship between the team and their fans for a long time(Soebbing, 2014) (Hill, 2000). The supporters or fans also want to hang out and take 
pictures with their favorite players. In addition, fans also buy souvenirs and items that the players use to show moral support and interest in their favorite players. Therefore, the introduction of players can attract fans to attend sporting events and support their favorite teams(Jr., 2016).

According to Shobian (2016), fans are associated with the team based on the individual players, the team's past or present win or lose ratio, promotional activities, marketing campaigns and home or guest team efficiency. Various promotions that have been offered such as fireworks shows, lucky draw prizes and so on. This can increase or decrease the membership identity of the team. This can also tend to improve fans' attendance at sporting events(Jr., 2016). It is obvious that after reviewing many articles, several scholars have both their consistencies and inconsistencies. For example, large fireworks displays, and prizes have attracted fans to attend sporting events (Paul, 2007).

Research has found that attendance motivations range from social dimensions to on site entertainment, but a review of this work also highlights the lack of empirical research on gender based attendance motives. The opportunities to disengage from life's routine as well as the entertainment value of the event have been presented in previous studies as significant attendance motives(O'Mahony, 2006).

In summary, numerous factors have been found to influence sports attendance, few studies report on the difference between male and female attendance motives. This study is designed to address this deficiency by comparing the attendance motives of males and females and presenting strategies to improve female attendance at sporting events (Hall, 2006).

\section{Methodology}

The sample of the study was selected from the ultras Boys of Straits Johor because football fans will follow the official website of Johor Southern Tigers page to get information about the progress of the team, matches and also other information about Johor Football Association. Based on the ultras Boys of Straits followers that get from Boys of Straits Johor official website, approximately 3,000 followers are the fans of the Johor Darul Ta'zim football match. The size represented by the 3,000 followers is the population size (N), so the sample size (S) will be 341 respondents(Morgan, 1970). Taking into consideration possible missing data, an additional $20 \%$ (68) of samples will be considered. So that, the total numbers of respondents who will be involved in the study becomes 409 . In addition, this study has been done through e-survey research because of the current situation during the pandemic of Covid-19.

The items of questionnaire were adopted and adapted from previous research done by Shobian (2016). The questionnaire will be provided in two languages which cover both Malay and English language. In the present study, a structured questionnaire consisting of two sections was prepared for used in the field of survey and collecting data. The data for this study will be collected through a set of questionnaires consisting of two sections which each section measures each of the variables that are relevant to the purpose of the study. Section A consisted of a standard list of demographics with seven questions in total, including gender, age, marital status, race, level education, occupational sector and monthly income. All of which had been noted as important variables in the factors influencing the fans decision between genders to attend football matches at Larkin Stadium. The second section contains 36 items designed to assess six different factors for involvement as a sports fan. The dimensions are residual preferences, economic, social aspects, enjoyment, team 
identification and team affiliation. The survey questions for each dimension are based on a 5point Likert Scale, with responses ranging from "Strongly Disagree" (1) to "Strongly Agree" (5) items to measure. To make it clear, the residual preferences component has 6 items, economic component has 5 items, social aspects component has 4 items, enjoyment component 5 has items, team identification component has 4 items and team affiliation component has 5 items.

The researcher used IBM Statistical Package for Social Science (SPSS) system version 26 to illuminate and assess the collected data. The data from the pilot study were analysed for its reliability values. The overall reliability for all domains showed 0.73 to 0.93 value set by the researcher. After the pilot study was conducted, the research was conducted onto the actual sample. A normality test is used to test if the data is normally distributed. The researcher used Kolmogorov-Smirnova to declare the normality of the distribution because the number of samples was more than 50 (Prabhakar Mishra, 2019). The results showed the significant value 0.10 which $p<0.05$, so that the data distribution was normal and the researcher used parametric statistical analysis.

\section{Findings}

In conducting the first objective of this study, Table 1 which presents a descriptive statistical analysis was used to identify the factor that most influences fan attendance during football matches at Larkin Stadium. In addition, the researcher used an inferential statistic to fulfill the second objective (Table 2 ) which presents the factors influencing the fans decision between genders to attend football matches at Larkin Stadium.

Table 1

Results of Descriptive of the Factors Influencing the Fans Attendance during Football Matches at Larkin Stadium

\begin{tabular}{lll}
\hline & & Descriptive Analysis \\
\hline & Mean & SD \\
Residual Preferences & 3.76 & .56 \\
Economics & 3.62 & .66 \\
Social Aspects & 4.06 & .64 \\
Enjoyment & 4.00 & .59 \\
Team Identification & 3.91 & .79 \\
Team Affiliation & 3.83 & .69 \\
\hline
\end{tabular}

Descriptive statistic including means and standard deviations of all variables are presented in the table above. From all the factors above, it shows that the social aspects with mean 4.06 and standard deviation 0.64 turned out to be the one factor that most influences fan's attendance during football matches at Larkin Stadium. Meanwhile, the factor that least attracts fans to come to the stadium is the economics factor that shows the lowest value of mean 3.62 and standard deviation 0.66. The difference value between highest mean and lowest mean was 0.44 . 
INTERNATIONAL JOURNAL OF ACADEMIC RESEARCH IN BUSINESS AND SOCIAL SCIENCES Vol. 11, No. 9, 2021, E-ISSN: 2222-6990 @ 2021 HRMARS

Table 2

Results of Independent Sample T-test of the Factors Influencing the Fans Decision between Genders to Attend Football Matches at Larkin Stadium

\begin{tabular}{lllllll}
\hline & Gender & $\mathrm{N}$ & Mean & $\begin{array}{l}\text { Std. } \\
\text { Deviation }\end{array}$ & $\begin{array}{l}\text { Std. Error } \\
\text { Mean }\end{array}$ & P Value \\
\hline Residual & Male & 223 & 3.8341 & .54857 & .03673 & .002 \\
Preferences & Female & 186 & 3.6604 & .55219 & .04049 & \\
\hline Economics & Male & 223 & 3.7166 & .69700 & .04667 & .001 \\
& Female & 186 & 3.4946 & .58307 & .04275 & \\
\hline Social & Male & 223 & 4.0987 & .62540 & .04188 & .134 \\
Aspects & Female & 186 & 4.0027 & .66525 & .04878 & \\
\hline Enjoyment & Male & 223 & 4.0502 & .62182 & .04164 & .052 \\
& Female & 186 & 3.9355 & .55617 & .04078 & \\
\hline Team & Male & 223 & 4.0527 & .81150 & .05434 & .000 \\
Identification & Female & 186 & 3.7433 & .73679 & .05402 & \\
\hline Team & Male & 223 & 3.9256 & .69283 & .04640 & .002 \\
Affiliation & Female & 186 & 3.7086 & .67450 & .04946 & \\
\hline
\end{tabular}

The first factors influence the fan's attendance is residual preferences between different genders, Levene's test to see equality of variances shows $p$ value is 0.775 which is greater than the significance level $a=0.05(p>0.05)$, then the variance of male and female respondents, therefore, the statistical value read is in the column equal variances assumed with the results of analysis showing the $p$ value for T-Test is 0.002 which is less than the significance level $a=0.05(p<0.05)$, this means that there was significant difference in residual preferences between different genders $(t(407.0)=3.179 ; p<0.05)$. Descriptive analysis showed that the mean for male (Mean $=3.834$ and $S D=0.549$ ) had higher residual preferences compared to female (Mean $=3.660$ and SD $=0.552$ ).

The second factors influence the fan's attendance is economics between different genders, Levene's test to see equality of variances shows $p$ value is 0.003 which is lower than the significance level $a=0.05(p<0.05)$, then the variance of male and female respondents, therefore, the statistical value read is in the column equal variances assumed with the results of analysis showing the $p$ value for T-Test is 0.001 which is less than the significance level $a=$ $0.05(p<0.05)$, this means that there was significant difference in economics between different genders $(t(407.0)=3.507 ; p<0.05)$. Descriptive analysis showed that the mean for male (Mean $=3.717$ and SD $=0.697$ ) had higher economics compared to female (Mean $=3.495$ and SD $=0.583$ ).

The third factors influence the fan's attendance is social aspects between different genders, Levene's test to see equality of variances shows $p$ value is 0.845 which is higher than the significance level $a=0.05(p>0.05)$, then the variance of male and female respondents, therefore, the statistical value read is in the column equal variances assumed with the results of analysis showing the $p$ value for T-Test is 0.134 which is more than the significance level a $=0.05(p>0.05)$, this means that there was no significant difference in social aspects between different genders $(t(407.0)=1.501 ; p>0.05)$. Descriptive analysis showed that the mean for male (Mean $=4.099$ and $S D=0.625$ ) had higher social aspects compared to female (Mean = 4.003 and $S D=0.665)$.

The fourth factors influence the fan's attendance is enjoyment between different genders, Levene's test to see equality of variances shows $p$ value is 0.132 which is higher than 
the significance level $a=0.05(p>0.05)$, then the variance of male and female respondents, therefore, the statistical value read is in the column equal variances assumed with the results of analysis showing the $p$ value for T-Test is 0.052 which is more than the significance level a $=0.05(p>0.05)$, this means that there was no significant difference in enjoyment between different genders $(t(407.0)=1.949 ; p>0.05)$. Descriptive analysis showed that the mean for male (Mean $=4.050$ and $S D=0.622$ ) had higher enjoyment compared to female (Mean = 3.936 and $\mathrm{SD}=0.556)$.

The fifth factors influence the fan's attendance is team identification between different genders, Levene's test to see equality of variances shows $p$ value is 0.094 which is higher than the significance level $a=0.05(p>0.05)$, then the variance of male and female respondents, therefore, the statistical value read is in the column equal variances assumed with the results of analysis showing the $p$ value for T-Test is 0.000 which is less than the significance level $a=0.05(p<0.05)$, this means that there was significant difference in team identification between different genders $(t(407.0)=4.003 ; p<0.05)$. Descriptive analysis showed that the mean for male (Mean $=4.053$ and $S D=0.812$ ) had higher team identification compared to female (Mean $=3.743$ and $S D=0.737$ ).

The last factors influence the fan's attendance is team affiliation between different genders, Levene's test to see equality of variances shows $p$ value is 0.770 which is higher than the significance level $a=0.05(p>0.05)$, then the variance of male and female respondents, therefore, the statistical value read is in the column equal variances assumed with the results of analysis showing the $p$ value for T-Test is 0.002 which is less than the significance level $a=$ $0.05(p<0.05)$, this means that there was significant difference in team affiliation between different genders $(t(407.0)=3.192 ; p<0.05)$. Descriptive analysis showed that the mean for male (Mean $=3.926$ and $S D=0.693$ ) had higher team affiliation compared to female (Mean = 3.709 and $S D=0.675)$.

\section{Discussion}

Based on the findings from descriptive statistic, the results of the study imply that the factor that most influences fan attendance during football matches at Larkin Stadium is social aspects factor. Social aspects are the relationship that is developed by individuals through interactions with other people in the society. Based on the current study, social aspects factor means involvement between the fans with family members, friends and people around. This causes these social aspects factor to be the most influential factor among other factors. This social aspect causes many fans that come to the stadium to watch the football match as they are able to interact with others and are able to meet new people when attending the stadium. In addition, fans can also spend time with family when attending the stadium. Next, the fans also came to the stadium because their friends also attended to watch the football match at the stadium. Meanwhile, these social aspects factor also has been supported by the previous journal. According to Wann and Branscombe (1991), when someone comes to the stadium to follow friends to be a cheerleading team, he will be happier and more enthusiastic to support their team. Another supported previous study from Kahle (2008), individual or groups who come to the stadium for following friends to become a cheerleading team are called a great accumulation of people which is part of social identification.

This research also identified the factors influencing the fans decision between genders to attend football matches at Larkin Stadium that has no significant difference which were social aspects factor and enjoyment factor. However, between these two factors influencing the fans decision, social aspects factor is proved to be the most common that has no 
difference factor influencing the fans decision between genders. The social aspects factor has no significant difference because the nature of the individual itself. When a fan wants to go to the stadium, the person will follow his friends. If, his friends do not want to go to the stadium, he also does not want to go to the stadium to watch football matches. This is also same with the family. If one's family does not want to go to the stadium, he will also not want to go to the stadium to watch the football match. Moreover, the nature of a person who does not like to associate with others has also given effect to why this social aspects factor has not significant difference. For example, a person would rather sit alone at home than attend a crowded place such as a stadium. This study was supported by the previous journal. According to Karakaya (2016), the study found that social aspect factors were not related to the presence of fans to the stadium. For another supported previous study by Kim and Trail (2010), this study found that the reason why fans did not attend the stadium was due to various internal and external restrictions. According to Binjwaied, Richards and O'Keeffe (2015), many football fans do not like to attend the stadium due to frequent fights between fans of home team and fans of the opposing team. This has led to many untoward incidents involving fans.

Next, enjoyment factor also has no significant difference. The reason why the enjoyment factor has no significant difference because most of the fans are fans that always come to the stadium to watch the game and their source of enjoyment is only the matches. They come to enjoy the match and they are not interested in watching the fireworks or any other shows. Football fans are not necessarily a football player. That is why to enjoy going to the stadium because of the memories of them being a player is not the source of enjoyment. This study also supported by the previous study. According to Paul (2003), their team performance will be the cause of the fans not feeling enjoy. It is because the fans were present with the intention of witnessing of thrilling action, but they could see the opposite. It will do little to dampen the spirits of the fans who come to the stadium to watch the football match. Thus, the enjoyment for this fan, come for a good football match.

\section{Conclusion}

The result of this study points out that the factors influencing the fans decision between genders to attend football matches at Larkin Stadium listed in the questionnaire do influence the fans to come and it was proven by the analysis. The factors that are significant with the fan's attendance are residual preferences, economics, team identification and team affiliation. While the factors that are not significant are social aspects and enjoyment. However, the social aspects factor has the highest mean which shows that most fans are going to the stadium to socialize with their friends, family or public in addition to watching the football match. In general, the fans backgrounds are mostly single young people who are still studying or have graduated with a degree. There are not much different in the number of male and female fans who attend the stadium. Furthermore, the Malay fans are more likely to go to the stadium compared to the Chinese and Indian fans. It can be concluded that all the objectives were achieved. The results of the study can bring the positive effects and improvement can be made towards the factors that will make the stadium in its best shape. This is to make sure that fans will satisfy with all the factors and make sure they will feel comfortable to come to the stadium. Perhaps, all the factors will become significant with the fan's attendance in the future. It can be concluded that all the objectives in this study were achieved. 


\section{References}

Alkubati, S. (2014). Health care workers' knowledge and practices regarding the prevention of central venous catheter-related infection. American Journal of Infection Control.

Beth, A., Cianfrone, J. J. (2015). Identifying Key Market Demand Factors Associated with High School Basketball Tournaments. Sport Marketing Quarterly, 91-104.

Binjwaied, M. (2015). The Factors Influencing Fans' Attendance at Football Matches in the Kingdom of Saudi Arabia. Athens Journal of Sports, 111-122.

Mastromartino, B. W.-H. W. (2018). The Passion That Unites Us All: The Culture and Consumption of Sports Fans. Sports Medicine, 1-34.

Branscombe, D. W. (1970). Sports fans: Measuring degree of identification with their team. International Journal of Sport Psychology , 1-17.

Hall, J. (2006). An empirical analysis of gender differences in sport attendance motives. International Journal of Sports Marketing \& Sponsorship, 334-346.

Hall, J. (2009). A model of predictors of attendance at major sporting events.

Havitz, C. B. (2010). Exploring the relationship between involvement, fan attraction, psychological commitment and behavioural loyalty in a sports spectator context. International Journal of Sports Marketing and Sponsorship, 140-157.

Hill, B. \&. (2000). Repeat attendance as a function of involvement, loyalty and the sportscape across three football contexts. . Sport Management Review, 145-162.

Hudson, M. (2010). Factors that influence Cal Poly students' decision to attend sporting events and theatrical performances.

Jr., M. S. (2016). Factors Affecting Spectators' Decision in Attending Minor League Baseball Home Games . MSL Academic Endeavors, 1-91.

Kahle, L. (2008). Social Values in Consumer Psychology. Handbook of Consumer Psychology, 576-585.

Karakaya, Y. K. (2016). Factors impacting the decision to attend soccer games:an exploratory study. . Sport, Business and Management: An International Journal, 320-340.

Morgan, R. V. (1970). DETERMINING SAMPLE SIZE FOR RESEARCH. EDUCATIONAL AND PSYCHOLOGICAL MEASUREMENT, 607-610.

Msar, S. (2019). Penyokong JDT kekal rekod cemerlang. Retrieved from My Metro: https://www.hmetro.com.my/arena/2019/10/511763/penyokong-jdt-kekal-rekodcemerlang

O'Mahony, J. H. (2006). An empirical analysis of gender differences in sports attendance motives. International Journal of Sports Marketing and Sponsorship, 39-51.

Paul, A. K. (2003). Impact of people management practices on organizational performance: Analysis of a causal model. . The International Journal of Human Resource Management, 1246-1266.

Paul, R. J. (2007). Attendance in the NY-Penn Baseball League: Effects of performance, demographics, and promotions. . New York Economic Review, 72-81.

Phillips, B.-R. (2018, December 10). My Health Record: legal challenges. Retrieved from InSight: https://insightplus.mja.com.au/2018/48/my-health-record-legal-challenges/

Mishra, P. C. P. (2019). Descriptive Statistics and Normality Tests for Statistical Data. Annals of Cardiac Anaesthesia, 67-72.

Soebbing. (2014). The effect of price dispersion on Major League Baseball team attendance. Journal of Sport Management, 433-445. 
Thielen, J. V. (2018). 5 guidelines for attracting more fans to soccer stadia. Retrieved from https://jeffvanthielen.com/2018/02/05/5-guidelines-for-attracting-more-fans-tosoccer-stadia/

Trail, Y. K. (2010). Constraints and Motivators: A New Model to Explain Sport Consumer Behavior. Journal of Sport Management, 190-210. 